\title{
Analysis of selected aspects of collective water supply system operation in the selected municipality
}

\author{
Krzysztof Boryczko ${ }^{1, *}$ \\ ${ }^{1}$ Rzeszow University of Technology, The Faculty of Civil and Environmental Engineering and \\ Architecture, Faculty of Management, Poznańska 2, 35-084 Rzeszów, Poland
}

\begin{abstract}
The purpose of the work was to analyze the exploitation of the collective water supply system (CWSS), on the example of Czudec, Podkarpackie CWSS. The water balance was prepared. The system operation was simulated using the Epanet software. The obtained data was presented in graphical form of pressure distribution on the network during the minimum and maximum demand. Water age simulations were also prepared, that is, the period of water residence in water distribution subsystem.
\end{abstract}

\section{Introduction}

Collective water supply systems (CWSS) existed already in antiquity, but in the 20th century that were introduced on a mass scale, which increased the hygiene of society's life. A significant increase in the length of the water supply network was observed at the end of the 20th century and in the 21st century, in particular in rural areas. In 1989, the length of the water supply network in Poland was 88.3 thousand $\mathrm{km}$, while in 2014 it increased to 292.5 thousand $\mathrm{km}$. The result of building new networks is increase people number who can use tap water. The percentage of urban and rural water supply has risen from $84.8 \%$ in 2002 to $91.6 \%$ in 2014, while $84 \%$ used it in rural areas in 2014, and $96 \%$ in urban areas. Acceleration of investments related to the build of water distribution subsystem (WDS) is related to the possibility of obtaining European funds by water companies and municipalities $[4,5,6,8,9]$.

Water companies in Poland consume water primarily for industrial and household purposes. The highest water consumption took place in the second half of the 20th century. This was caused by low price of water. The increasingly water quality standards have forced companies to develop newer and more expensive water treatment technologies, which resulted in a drastic increase in prices [1-3]. The result was a reduction of water consumption per statistical inhabitant [7].

In the era of computerization, managers of water supply companies use computer programs that enable monitoring of water distribution subsystem, its correct operation, as well as the ability to quickly eliminate water pipes failures. The aim of the paper is analysis of the WDS Czudec commune operation.

*Corresponding author: kb@prz.edu.pl 


\section{Description of the analyzed system of collective water supply}

The water distribution subsystem was created relatively recently. The first water pipes were built in 1994. Before that time, the inhabitants took water from their own individual wells. For the next 9 years, the water supply network did not increase. The breakthrough year was 2003, because the residents of the commune were running out of water. At that time, a decision was made to further expand WDS. It consists pipes with diameters: $\varnothing 50, \varnothing 63$, $\varnothing 90, \varnothing 110, \varnothing 125, \varnothing 160, \varnothing 225$. The main material that was used to build the network is polyethylene (PE). Table 1 presents the characteristics of the WDS in 2009-2016.

Table 1. Characteristics of the WD in the Czudec commune in 2009-2016

\begin{tabular}{|c|c|c|c|c|c|}
\hline \multirow{2}{*}{ year } & Length & diameter & $\begin{array}{c}\text { Number of } \\
\text { residents }\end{array}$ & $\begin{array}{l}\text { Number of residents } \\
\text { connected to WDS }\end{array}$ & $\begin{array}{c}\% \text { residents } \\
\text { connected to WDS }\end{array}$ \\
\hline & {$[\mathrm{km}]$} & {$[\mathrm{mm}]$} & {$[-]$} & {$[-]$} & [\%] \\
\hline until 2009 & 86.569 & & 11569 & 2606 & 22.5 \\
\hline 2010 & 108.047 & - & 11588 & 3251 & 28.1 \\
\hline \multirow{4}{*}{2011} & 1.250 & $\varnothing 63$ & \multirow{4}{*}{11749} & \multirow{4}{*}{3265} & \multirow{4}{*}{27.8} \\
\hline & 0.750 & $\varnothing 110$ & & & \\
\hline & 5.750 & $\varnothing 160$ & & & \\
\hline & 3.080 & $\varnothing 225$ & & & \\
\hline$\Sigma$ & 118.877 & & & & \\
\hline \multirow{2}{*}{2012} & 3.765 & $\varnothing 110$ & \multirow{2}{*}{11777} & \multirow{2}{*}{3278} & \multirow{2}{*}{27.8} \\
\hline & 5.835 & $\varnothing 160$ & & & \\
\hline$\Sigma$ & 128.477 & & & & \\
\hline \multirow{2}{*}{2013} & 4.139 & $\varnothing 50$ & \multirow{2}{*}{11721} & \multirow{2}{*}{3325} & \multirow{2}{*}{28.4} \\
\hline & 4.832 & $\emptyset 110$ & & & \\
\hline$\Sigma$ & 137,448 & & & & \\
\hline \multirow{3}{*}{2014} & 0.024 & $\varnothing 63$ & \multirow{3}{*}{11723} & \multirow{3}{*}{3461} & \multirow{3}{*}{29.5} \\
\hline & 1.662 & $\varnothing 110$ & & & \\
\hline & 0.721 & $\varnothing 160$ & & & \\
\hline$\Sigma$ & 139.855 & & & & \\
\hline \multirow{5}{*}{2015} & 0.976 & $\varnothing 50$ & \multirow{5}{*}{11788} & \multirow{5}{*}{4139} & \multirow{5}{*}{35.1} \\
\hline & 0.374 & $\varnothing 63$ & & & \\
\hline & 0.081 & $\varnothing 90$ & & & \\
\hline & 10.321 & $\varnothing 110$ & & & \\
\hline & 1.345 & $\varnothing 125$ & & & \\
\hline$\Sigma$ & 152.952 & & & & \\
\hline \multirow{7}{*}{2016} & 1.351 & $\varnothing 50$ & \multirow{7}{*}{11798} & \multirow{7}{*}{4680} & \multirow{7}{*}{39.7} \\
\hline & 0.134 & $\varnothing 63$ & & & \\
\hline & 0.731 & $\varnothing 90$ & & & \\
\hline & 10.504 & $\varnothing 110$ & & & \\
\hline & 1.223 & $\emptyset 125$ & & & \\
\hline & 0.336 & $\emptyset 140$ & & & \\
\hline & 0.328 & $\varnothing 160$ & & & \\
\hline$\Sigma$ & 167.559 & & & & \\
\hline
\end{tabular}

At the end of 2016, the total length of WDS was $167.56 \mathrm{~km}$, and the percentage of people connected to WDS reached $39.7 \%$. The population of the Czudec commune in period 2009-2016 increased by 229 people and the number of water recipients at the end of 2016 reached 4680.

As shown in Figure 1, water intake increases. The exception is 2014, when it was 15.08 thousand $\mathrm{m}^{3}$ of water less than in the previous year. A significant increase in water sales is 
also observed, which is associated with the WDS growth. In the period under analysis, a large drop in water losses can also be noticed.

Figure 2. present diagram of the WDS in the Czudec commune.

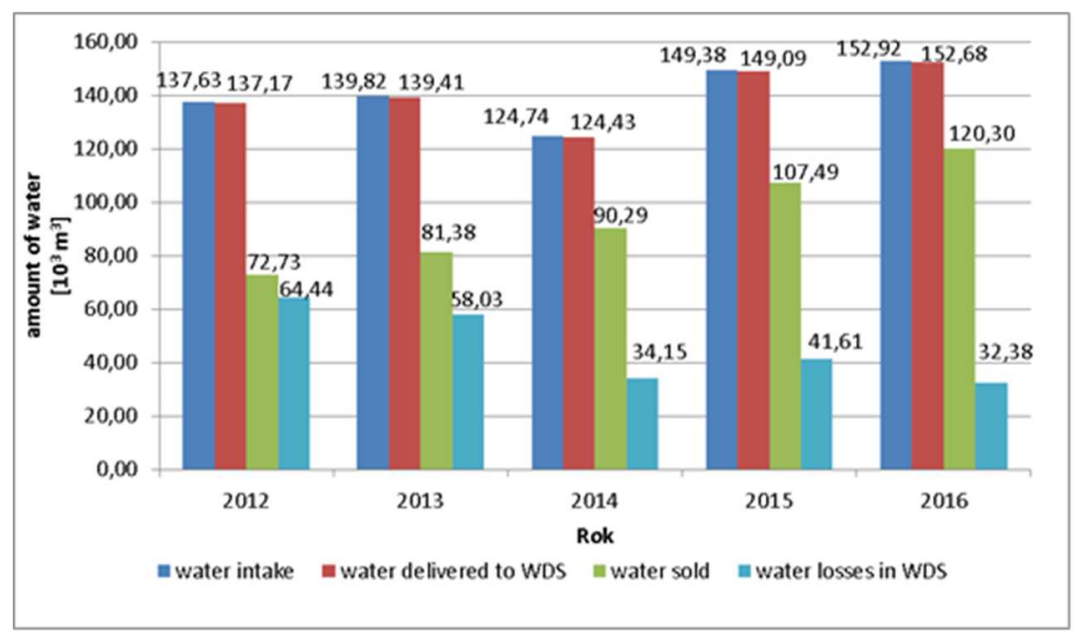

Fig. 1. Water balance in the municipality of Czudec

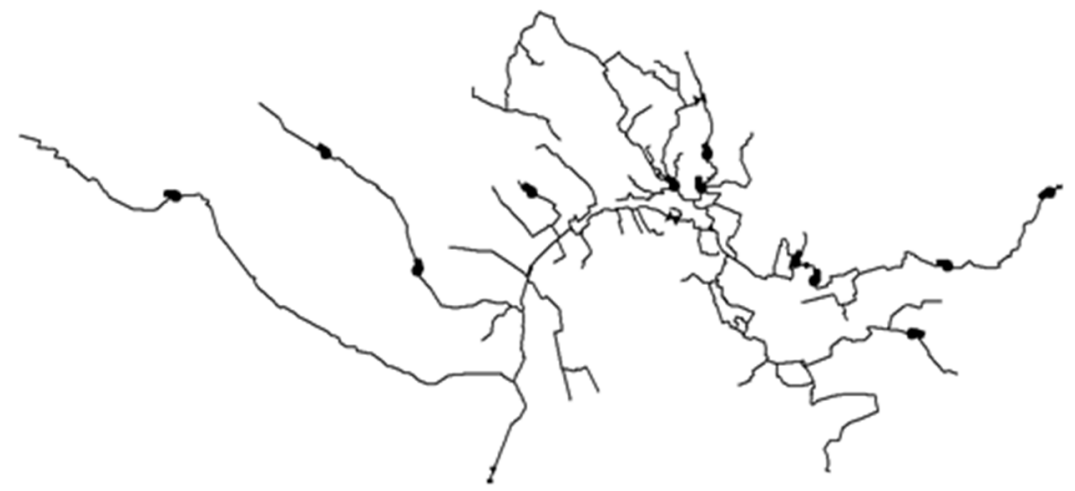

Fig. 2. Diagram of the WDS in the Czudec commune

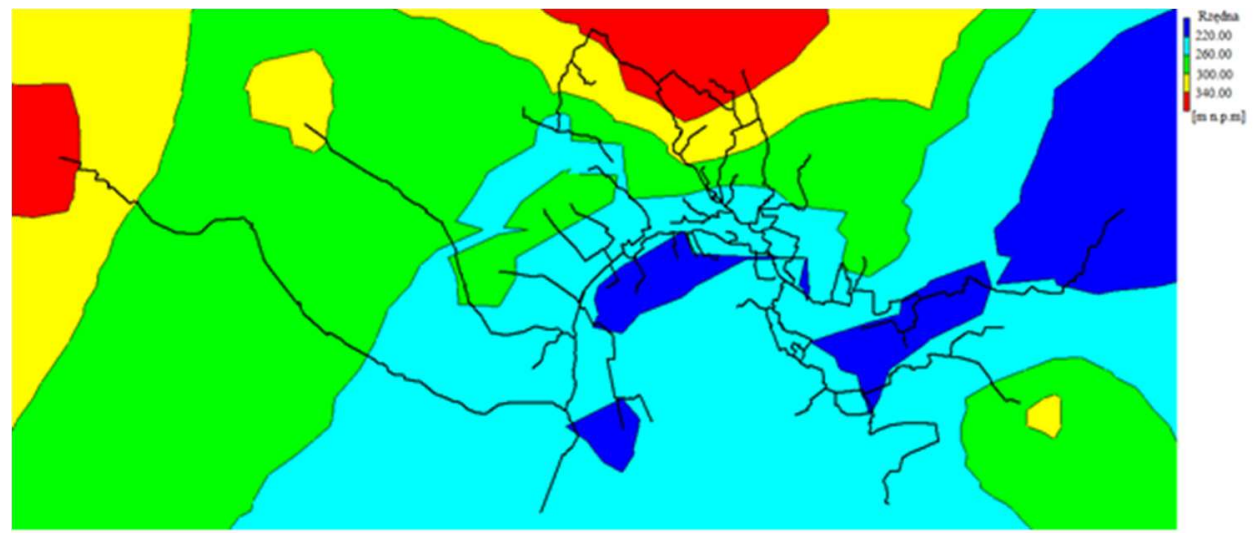

Fig. 3. The height layout of WDS in the Czudec commune 
Water intakes and tanks are located in the southern and eastern part of the commune, and pumping stations are located on the entire surface of the supply area.

Czudec commune is located in a varied height. In figure 3 the height layout of WDS is presented.

\section{Analysis of the pressure in WDS}

For the purposes of the analysis, a hydraulic model of the water supply network was prepared. Figure 4 shows the distribution of pressure on the network during the minimum demand, while Figure 5 shows the frequency of pressure at the minimum demand.

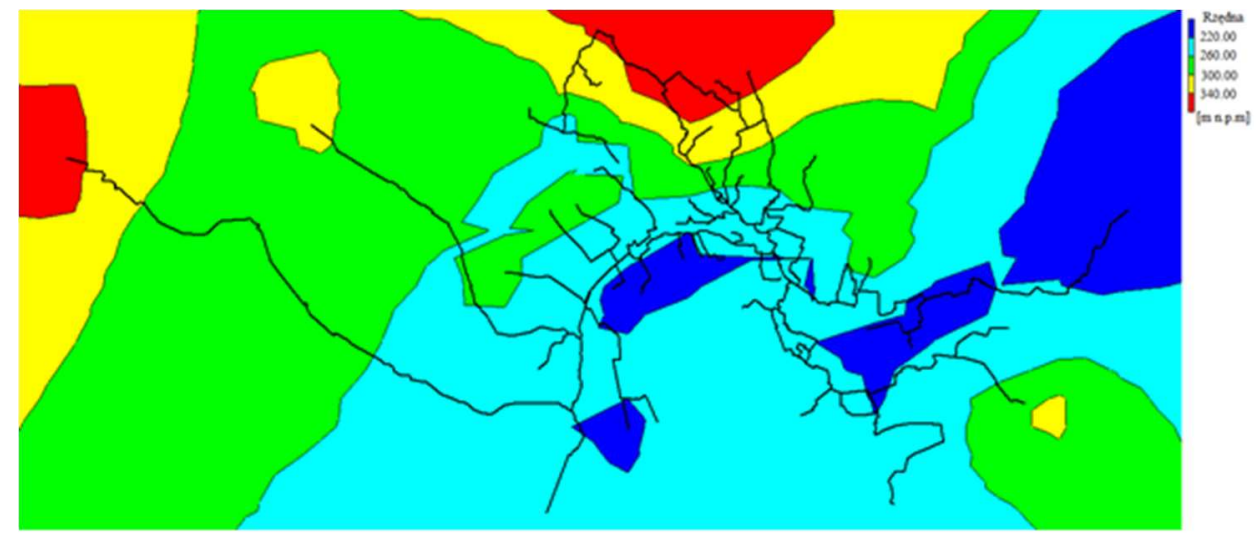

Fig. 4. Distribution of pressure on the network during the minimum demand

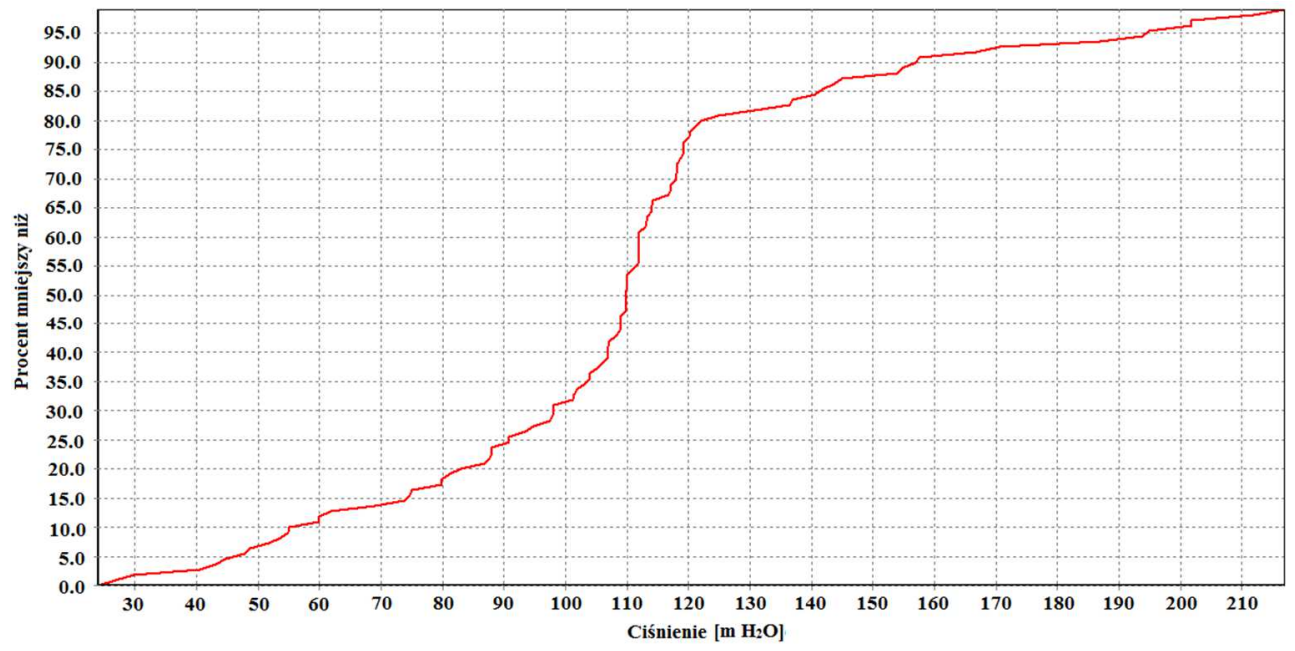

Fig. 5. Frequency of pressure occurrence during minimum demand (x-axis - pressure, y-axis - percent less than)

During the minimum demand, the pressure in the WDS ranges from 24 to $215 \mathrm{mH}_{2} \mathrm{O}$, of which pressures up to $110 \mathrm{mH}_{2} \mathrm{O}$ account for $50 \%$. The highest pressures occur in the northern part of the network and exceed the value of $120 \mathrm{mH}_{2} \mathrm{O}$.

Figure 6 shows the distribution of pressure during the maximum water demand, while Figure 7 shows the frequency of pressure during this demand. 


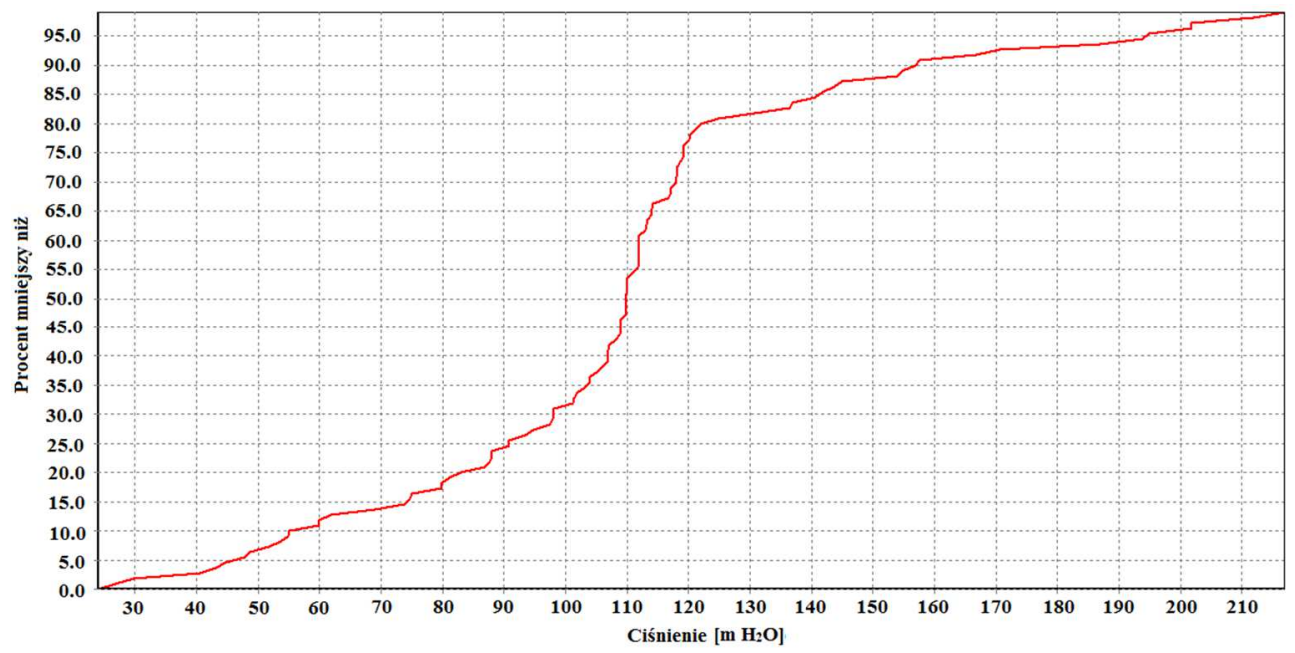

Fig. 6. Distribution of pressure on the network during the minimum demand

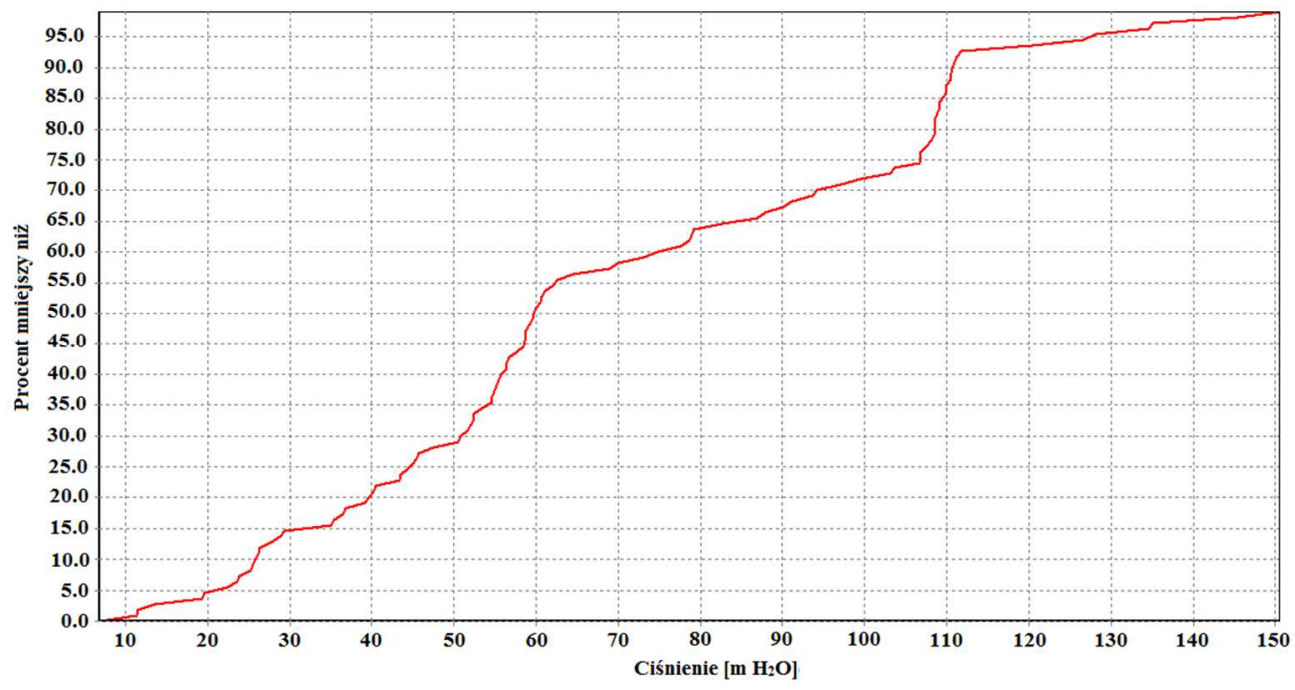

Fig. 7. Distribution of pressure on the network during the minimum demand (x-axis - pressure, $y$-axis - percent less than)

The highest pressure during the maximum water demand occurs in the north-western area of the WDS and exceeds $150 \mathrm{mH}_{2} \mathrm{O}$. The pressure during this demand is in the range from $7 \mathrm{mH}_{2} \mathrm{O}$ to about $150 \mathrm{mH}_{2} \mathrm{O}$, of which $50 \%$ are pressures below $60 \mathrm{mH}_{2} \mathrm{O}$.

\section{Water age analysis}

Water age simulations were also prepared, that is, the period of water residence WDS. This simulation is shown in Figure 8.

The lowest water age below 24 hours occurs in the central, eastern and south-western parts of WDS. In the northwest and the western water supply area, the age exceeds 96 hours. These are mainly the ends of WDS in which the demand is negligible. 


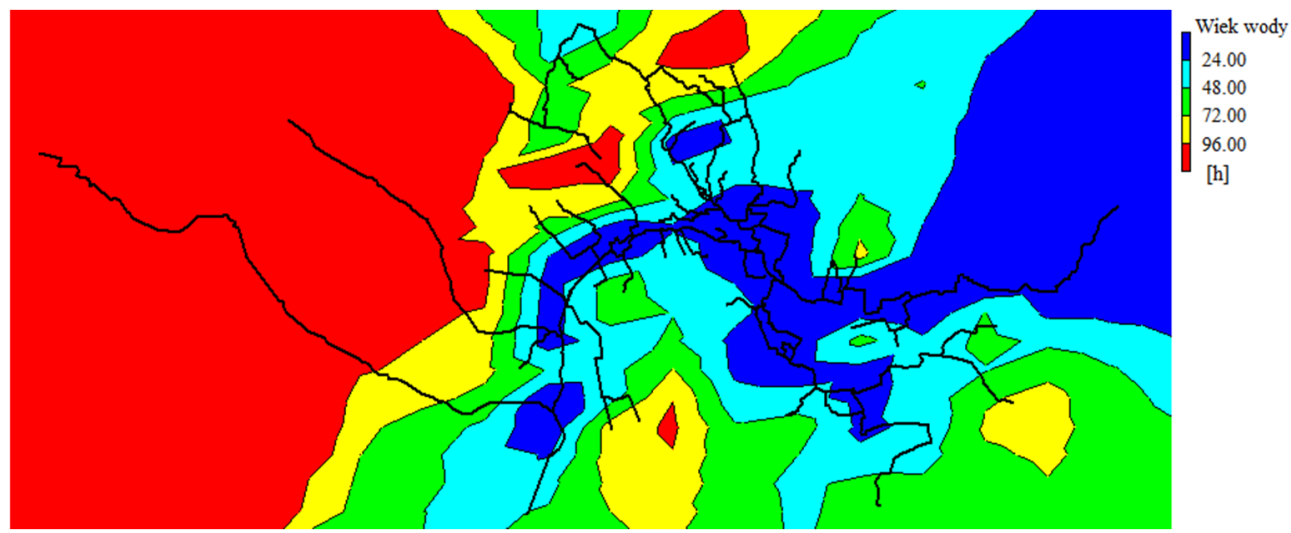

Fig. 8. Water age in the WDS

\section{Conclusions}

Proper operation of the CWSS allows to achieve continuous operation of the entire WDS, Thanks to hydraulic model it is possible to optimize the operation process.

During the minimum demand on a large part of the WDS, the pressure exceeds $60 \mathrm{~m}$ $\mathrm{H}_{2} \mathrm{O}$ - recommended maximum for house connections. The reason for such high pressures is mostly the terrain. In places where pressure exceeds $60 \mathrm{mH}_{2} \mathrm{O}$, pressure reducers are installed at house connections.

Due to the diversified terrain, there is no possibility of gravitational water supply entire WDS, therefore, where necessary, a pumping station is located (there are 11 pumping stations on the whole WDS).

The actions to be taken to reduce the pressure in WDS are primarily the installation of pressure reducers in regions where there is a gravitational supply of water. As a result, it is possible to reduce the risk of failure caused by the cracking of pipe due to high pressures. Another action that should be taken is the separation of more water pumping zones. This would reduce the lift height of the pump, and thus reduce the pressure, resulting in lower water losses.

\section{References}

1. Boryczko K. Water age in the water supply network as health risk factor associated with collective water supply, Ecol Chem Eng 23, pp 33-43, (2016)

2. Boryczko K., Rak J. Assessment of water supply diversification using the Pielou index, ENVIRONMENTAL ENGINEERING V, Pawlowski L. Pawlowska M., Editor,: CRC PRESS-BALKEMA, pp 53-58, Leiden, Netherlands (2017)

3. Calzadilla A., Rehdanz K.,. Tol R. S. J. The economic impact of more sustainable water use in agriculture: A computable general equilibrium analysis, J Hydrol 384, pp 292-305, (2010)

4. Miszta-Kruk K., Kowalski D. Failure of water supply networks in selected Polish towns based on the field reliability tests, Eng Fail Anal 12, pp 736-742, (2013)

5. Pietrucha-Urbanik K. Failure analysis and assessment on the exemplary water supply network, Eng Fail Anal, 57, pp 137-142, (2015)

6. Pietrucha-Urbanik K., Tchórzewska-Cieślak B., Urbanik M. Analysis of the gas network failure and failure prediction using the Monte Carlo simulation method, Eksploat Niezawodn, 18, pp 254-259, (2016) 
7. Studziński A. Amount of labour of water conduit repair, Safety, Reliability and Risk Analysis: Beyond the Horizon, Van Gelder P.H.A.J.M. Steenbergen R.D.J.M., Miraglia S., Vrouwenvelder A.C.W.M., Editor,: Taylor \& Francis Group, pp 2081-2084, London (2014)

8. Szpak D., Tchórzewska-Cieślak B. A Proposal of a Method for Water Supply Safety Analysis and Assessment, Ochrona Środowiska 37, pp 43-47, (2015)

9. Tchorzewska-Cieslak B., Szpak D. Water producers risk analysis connected with collective water supply system functioning, Dependability Engineering and Complex Systems. Advances in Intelligent Systems and Computing, W; Mazurkiewicz Zamojski, J; Sugier, J; et al., Editor, Springer pp. 479-489, Switzerland (2015) 